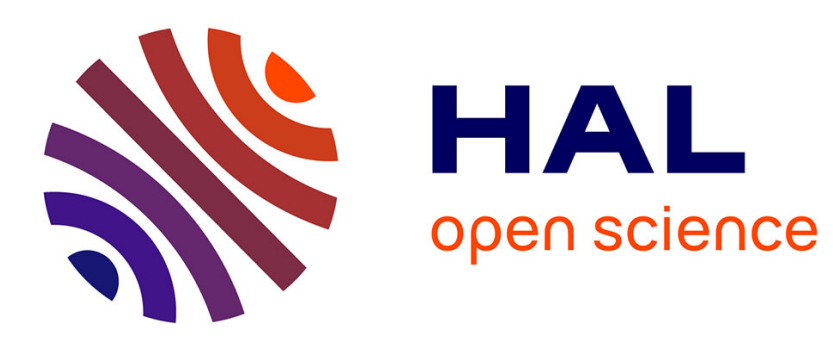

\title{
Characterization of the cure shrinkage, reaction kinetics, bulk modulus and thermal conductivity of thermoset resin from a single experiment
}

\author{
Yasir Nawab, Pascal Casari, Nicolas Boyard, Frédéric Jacquemin
}

\section{- To cite this version:}

Yasir Nawab, Pascal Casari, Nicolas Boyard, Frédéric Jacquemin. Characterization of the cure shrinkage, reaction kinetics, bulk modulus and thermal conductivity of thermoset resin from a single experiment. Journal of Materials Science, 2013, 48 (6), pp.2394-2403. 10.1007/s10853-012-7026-6 . hal-01005853

\section{HAL Id: hal-01005853 \\ https://hal.science/hal-01005853}

Submitted on 10 Mar 2018

HAL is a multi-disciplinary open access archive for the deposit and dissemination of scientific research documents, whether they are published or not. The documents may come from teaching and research institutions in France or abroad, or from public or private research centers.
L'archive ouverte pluridisciplinaire HAL, est destinée au dépôt et à la diffusion de documents scientifiques de niveau recherche, publiés ou non, émanant des établissements d'enseignement et de recherche français ou étrangers, des laboratoires publics ou privés. 


\title{
Characterization of the cure shrinkage, reaction kinetics, bulk modulus and thermal conductivity of thermoset resin from a single experiment
}

\author{
Yasir Nawab - Pascal Casari - Nicolas Boyard • \\ Frédéric Jacquemin
}

\author{
Y. Nawab · N. Boyard \\ Laboratoire de Thermocinétique de Nantes, LUNAM Université, \\ Université de Nantes, UMR CNRS 6607, La Chantrerie, rue \\ Christian Pauc, BP 50609, 44306 Nantes Cedex 3, France \\ Y. Nawab $(\bowtie) \cdot$ P. Casari · F. Jacquemin ( $\square)$ \\ Institut de Recherche en Génie Civil et Mécanique, LUNAM \\ Université, Université de Nantes, UMR CNRS 6183, 37 \\ Boulevard de l'université, BP406, 44600 Saint-Nazaire, France \\ e-mail: yasir.nawab@yahoo.com \\ F. Jacquemin \\ e-mail: frederic.jacquemin@univ-nantes.fr
}

\section{Introduction}

Composite materials have become a popular choice due to their super light weight, and superior mechanical properties among naval, aerospace and automobile industries. Frequent problems, e.g. shape distortion, fibre buckling and matrix cracking, etc., are faced during production as a consequence of the heterogeneous nature of such materials. Excellent control of the curing process is required for production of a composite part with required shape and properties. For an accurate simulation of the curing process, exact knowledge of cure-dependent polymer properties and heat transfer is needed [1-4]. Development of matrix properties, chemical shrinkage and thermal conductivity are strongly coupled with the degree of cure. In general, these are characterized with different instruments which may lead to the prejudicial results. Moreover, use of several instruments for determination of different parameters is time consuming and expensive. Therefore, a device which is able to measure several matrix/composite properties in controlled conditions may be very interesting.

In the present article, results on the simultaneous characterization of chemical shrinkage, degree of cure and bulk modulus of vinylester resin during curing, in temperature ramp conditions, done by a home-built instrument (PVT- $\alpha$ mould) are presented. Comparison of the obtained degree of cure is made with the results of a differential scanning calorimeter. The chemical shrinkage curve is also compared with literature results.

Temperature and cure dependent thermal conductivity of same resin is also determined using this instrument. The obtained results are compared with the measurements by a classical 'hot guarded plate' technique.

Literature on the determination of the above-mentioned properties is reviewed briefly in the following paragraphs. 
Degree of cure and chemical shrinkage

Degree of cure or conversion degree is an indication of extent of cross-linking of molecules. Since several properties of matrix develop with network formation of molecules, it is common to present these as a function of the degree of cure. As cross-linking of thermoset molecules is exothermic, consequent released heat has been frequently used for determination of degree of cure [5]. A popular device used for this purpose is a differential scanning calorimeter (DSC). Degree of cure is deduced by integrating enthalpy of reaction of the scanned sample.

Thermoset matrix shrinks due to cross-linking of molecules during the curing. Chemical shrinkage is a key parameter for modelling of the curing process, and has been studied by many authors [6-9] in the recent past. Identification techniques include capillary-type dilatometer $[10,11]$, plunger type dilatometers [12-14], gravimetric method [9, 15], rheometer [16], pycnometer [16, 17], fibre Bragg grating [18-22], thermo mechanical analyzer [23], dynamic mechanical analyzer [24, 25], ultrasonic waves [8] using optical fibres etc. These devices measure the volume (or length) variation during curing. Subtraction of thermal expansion (if any) from total volume (or length) change, results into value of chemical shrinkage.

Figure 1 shows the examples of results on volume chemical shrinkage of various resin system. Boyard et al. [26] presented the results on volume chemical shrinkage of unsaturated polyester containing additives. Dilatometry was carried out in mould PVT- $\alpha$, and thermal expansion was subtracted from the total volume of resin while neglecting the thermal gradients. Resultant volume chemical shrinkage is presented versus degree of cure in Fig. 1b, which is linear. Abou-Msallem [27] reported volume chemical shrinkage of M21 epoxy resin versus degree of cure, which was found linear. A linear behaviour of volume chemical shrinkage versus degree of cure was presented by Holst et al. [28] as shown in Fig. 1c. Nawab et al. [6] noted that volume chemical shrinkage of vinylester resin versus degree of cure is linear when thermal gradients are neglected. Considering these gradients may affect the evolution of chemical shrinkage of resin but the total chemical shrinkage remains unaffected.

\section{Bulk modulus}

Bulk modulus $(K)$ is defined as the ratio of compressive stress (pressure) to the volume strain [29]:

$K=\frac{\sigma_{\text {volume }}}{\varepsilon_{\text {volume }}}$

It is an important factor to determine the behaviour of ballistic applications, and to feed the viscoelastic damage models to predict the overall viscoelastic behaviour of particle-reinforced polymeric composites undergoing damage [30]. It is also a key characteristic to define the compressive behaviour of composite parts, i.e. polymer reinforced concrete, etc., subjected to the compressive load. Moreover, Young's modulus can also be calculated from it using the classical Eq. (9) of mechanics, which is an important property to model the residual stresses [2, 27, 31] and shape evolution of composite part during curing [32].

A few authors have identified the bulk modulus of cured polymers. For example, Mott et al. [33] determined the bulk and shear moduli of cured polystyrene, and polymethyl methacrylate using longitudinal and shear waves, speeded at $1 \mathrm{MHz}$. Dixon [34] measured the bulk modulus of cured epoxy resin using an electromagnetic acoustic transducer (EMATs). Pleypys [35] measured the evolution of Young's modulus of epoxy resin using a strain gauge method, from which bulk modulus of cured resin was calculated.

Lindrose [36] is the one, who reported the measurement of evolution of bulk modulus of epoxy resin during curing using the ultrasonic waves. But this measurement was strongly limited to isothermal and non-exothermic conditions, as the speed of sound is very sensitive to temperature. The test took more than $24 \mathrm{~h}$. If composite curing is done in heating ramp conditions, the reactions are highly exothermic and this technique may not be able to give reliable results. In the recent years, Yang [25] adapted low frequency DMA to measure the in-cure bulk and shear moduli of epoxy resin containing fillers.

\section{Thermal conductivity}

Identification of the thermal conductivity is a primary parameter to define heat transfers in composite during the curing. The experimental methods found in literature can be categorized as: stationary methods, e.g. guarded hot plate [37], and transient methods [38].

Guarded hot plate method [37] is a simple method and is based on unidirectional Fourier's law. A sample with given thickness is placed between two plates having different temperatures. The temperature difference between two surfaces of the sample caused a heat flux through it. Using thickness of sample, temperature difference and heat flux, thermal conductivity for given temperature is calculated. An example of the determination of transient thermal conductivity is given in [38]. It consists in identifying thermal conductivity from temperature measurements done at several locations through the sample thickness.

\section{Description of PVT- $\alpha$ mould}

Classically, PVT- $\alpha$ mould has been used to study the neat thermosetting resin and composites during and/or after 

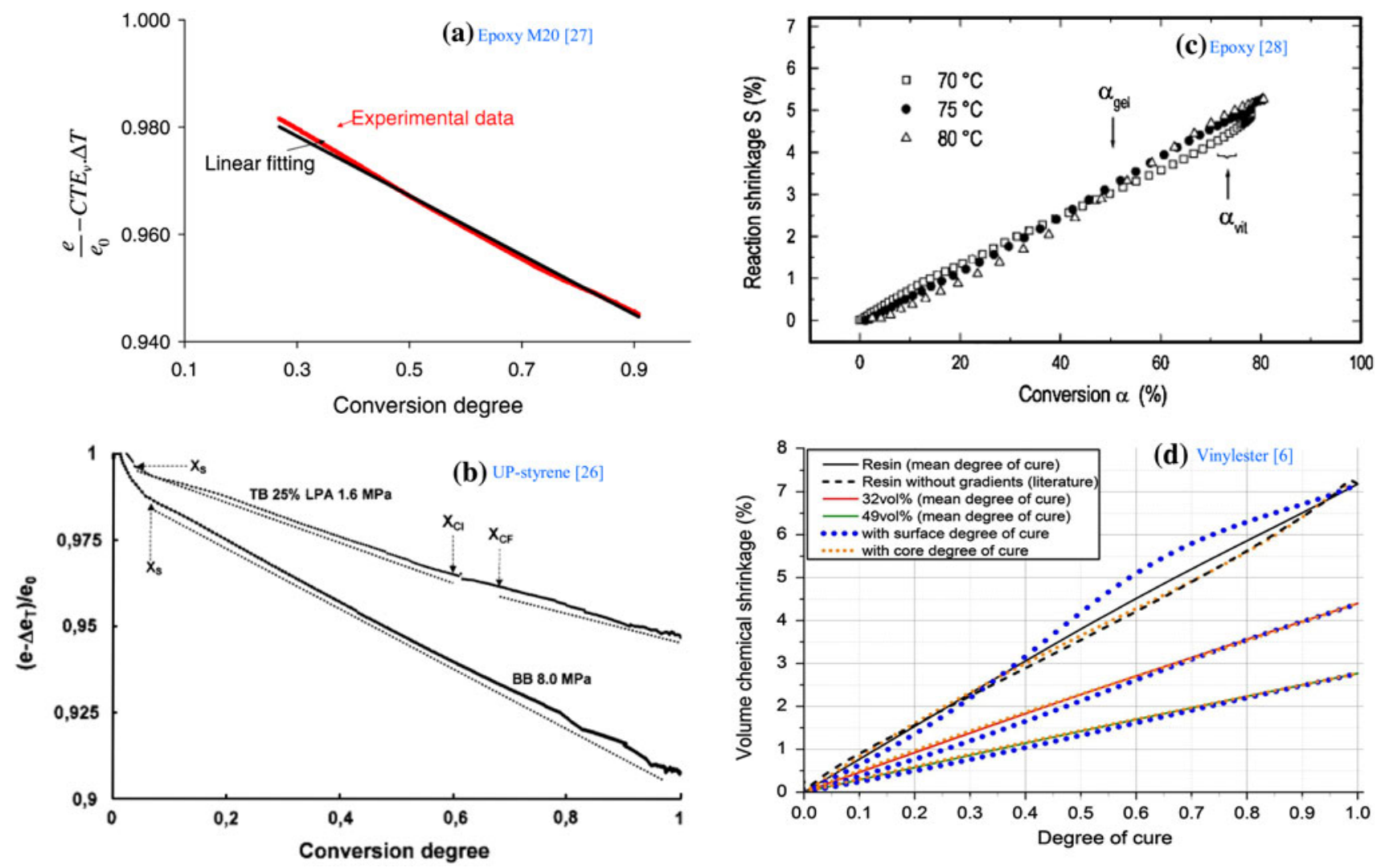

Fig. 1 Chemical shrinkage of different resin systems

curing under constant pressure conditions [7, 39, 40]. In addition, experiments can be done on bulk samples (several millimeters thick and $40 \mathrm{~mm}$ diameter). The instrument works in the conditions close to the industrial ones (i.e. adjustable pressure up to $10 \mathrm{MPa}$ in moulding cavity and temperature up to $200{ }^{\circ} \mathrm{C}$ ). It consists of a piston that can move in a cylindrical stainless steel cavity (Fig. 2) with a $51 \mathrm{~mm}$ internal diameter. Three heaters, located at the top and bottom, ensured the heating of piston and cavity, respectively. The cooling system consists of compressed air circuiting in the top and in the bottom of the mould. PID controllers allow the thermal regulation of the device. The mould is placed between two platens of an electric press. The position of the piston can be adjusted in real time to get the required pressure. Data treatment with a Beck inverse sequential algorithm [41] provides temperature and heat flux density at the surface of the sensor, exchanged between the sample and the mould. More details about this device are given in [26, 40].

Assuming that the thermal gradients are rather low, measured heat flux ' $\varphi$ ' can be written as:

$\varphi=m \cdot \bar{C}_{P} \frac{\partial \bar{T}}{\partial t}+m \cdot \Delta H \cdot \frac{\partial \bar{\alpha}}{\partial t}$

where ' $m$ ' is the mass of the sample, $\bar{C}_{P}$ is the meanspecific heat, $\bar{T}$ is the average temperature, $\Delta \mathrm{H}$ is the total heat released during the curing of the sample, and $\bar{\alpha}$ is the average degree of cure.

For the experiment in PVT- $\alpha$, the polymer is sealed in a low-modulus elastomer capsule to avoid the jamming of the mould. Injection of resin is facilitated by syringes and vacuum assistance, which avoid air bubbles too. The capsule is then placed in the mould cavity. Movement of piston to achieve the required pressure is recorded by LVDT-type displacement sensor with a precision of $1 \mu \mathrm{m}$ and a limit of $10 \mathrm{~mm}$. Thanks to the deformable but incompressible elastomer cavity, the surface of the elastomer, on which the pressure is applied, does not vary. As a consequence, the measured thickness is directly related to the sample volume and its variations.

For making PVT- $\alpha$ mould able to work for the first time in the dynamic pressure mode, the load cycle was controlled by a Labview program. The input load signals and actual response of the instrument was recorded by the data acquisition system along with other parameters, i.e. surface heat flux and temperatures of sample, etc. Figure 3 shows the input load signal and PVT- $\alpha$ actual load versus time. It can be noted that during the increasing load step, both input and actual signal superimposed. But during the unloading step, PVT- $\alpha$ lagged behind the input signal. This difference did not affect the results. However, the response of PVT- $\alpha$ 


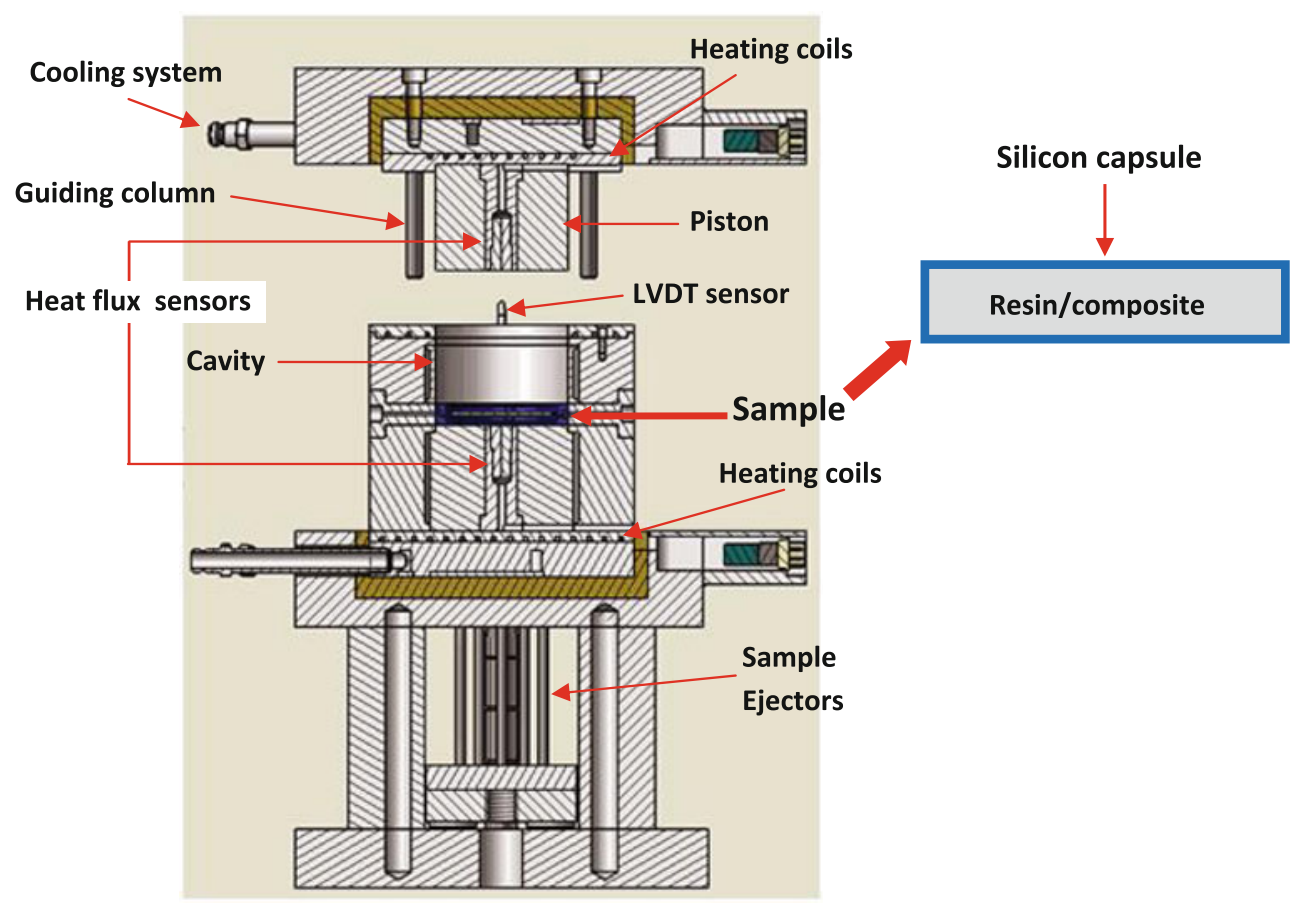

Fig. 2 A sketch of PVT- $\alpha$ mould device

in this step can be improved by replacing the motor that controls the piston, with a delicate one. Note that, upper and lower pressure bounds were kept constant for a few seconds to ensure that the imposed values had reached. Variation of pressure during the curing may affect the cross-linking kinetics of resin during curing. In order to minimize this effect, the pressure was varied in a short time period and then the system was maintained at a constant pressure.

\section{Materials and methods}

Vinylester resin (DERAKANE MOMENTUM 411-350 epoxy vinyl ester) was used with $0.05 \mathrm{wt} \%$ of initiator (Cobalt Naphthenate) and $1 \mathrm{wt} \%$ of Catalyst (NOROX MEKP-925H Methylethylketone peroxide (MEKP)). These proportions were selected to get maximum gel time at room temperature $\left(30 \pm 10 \mathrm{~min}\right.$ at $\left.25^{\circ} \mathrm{C}\right)$.

Experiments on PVT- $\alpha$ mould were done under two different pressure conditions:

1. Cyclic pressure as per following cycle (Fig. 3)
a. Maintaining at $3.35 \mathrm{MPa}$ for $40 \mathrm{~s}$,
b. Increasing to $6 \mathrm{MPa}$ in $10 \mathrm{~s}$,
c. Decreasing to $0.75 \mathrm{MPa}$ in $20 \mathrm{~s}$,
d. Increasing to $3.35 \mathrm{MPa}$ in $10 \mathrm{~s}$,

2. Constant pressure of $0.75 \mathrm{MPa}$ during the whole experiment.

For both pressure conditions, same thermal cycle was used for curing of samples:

a. Equilibrating the system at room temperature and maintaining for $2 \mathrm{~min}$,

b. Heating to $180{ }^{\circ} \mathrm{C}$ at rate of $4{ }^{\circ} \mathrm{C} / \mathrm{min}$ and maintaining for $10 \mathrm{~min}$,

c. Cooling to room temperature at $4{ }^{\circ} \mathrm{C} / \mathrm{min}$.

In a DSC, scanning of the samples was also done using the above thermal cycle.

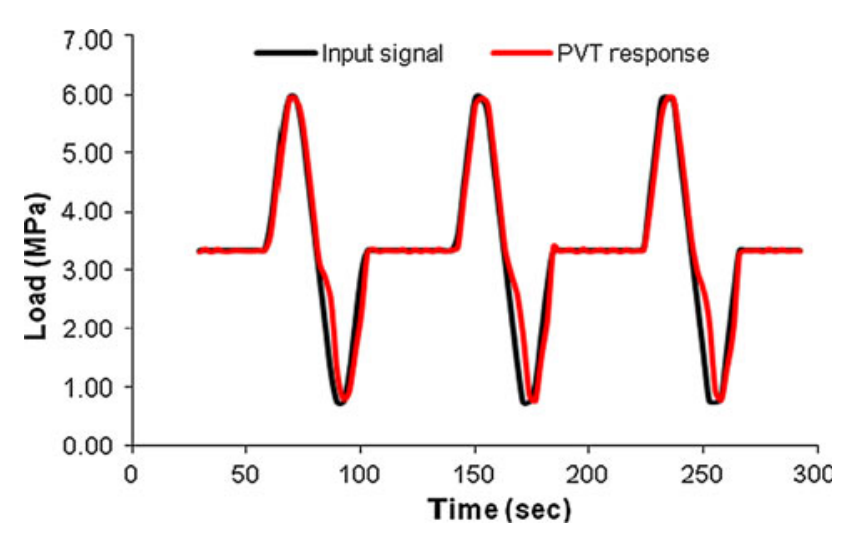

Fig. 3 Input load signal and PVT- $\alpha$ mould response versus time 


\section{Results and discussion}

Determination of degree of cure

Vinylester resin used in this study is a low-temperature polymerization resin, so care was taken to mix the catalyst and initiator in resin, and to inject it in the capsule as quick as possible to avoid the beginning of the reaction outside the instrument. In general, 5-7 min were taken after mixing step to start the PVT- $\alpha$ experiment. The acquisition system recorded the signals given by the six thermocouples of both heat flux sensors with respect to a cold junction, and the signal of the displacement sensor. In order to take into account possible heat losses of the mould and thermal expansions of the LVDT sensor, the elastomer and the mould, an aluminium disc with known properties was placed in the elastomer capsule to be submitted to the same thermal and pressure cycle as the sample. This data was then used as 'reference' experiment. After data treatment the total heat flux density $(\varphi)$, temperature $T$, and the thickness variation were obtained.

An example of recorded heat flux density (dynamic pressure) during the heating cycle applied on the neat resin is presented in Fig. 4a. Degree of cure found by integrating heat flux density curve is plotted in Fig. 4b.

In the beginning, when the reaction was not started, an endothermal effect of the heat flux density curve can be observed due to the heating of the sample. However, on increasing the temperature (Temp), the reaction started $(t \approx 450 \mathrm{~s})$, resulting in an exothermal peak. After about $1,350 \mathrm{~s}$ the resin got fully cured (or reaction became too slow to observe any effect on the heat flux curve). When the isothermal step was reached, heat flux curve returned to zero, showing that there was neither thermal nor chemical phenomenon involving heat transfers.

Total heat of cure was determined by integration of the heat flux curve using sigmoid base line. The degree of cure ( $\alpha$ ) was found using (Eq. 3):

$\alpha(t)=\frac{\int_{0}^{t} \phi \mathrm{d} t}{\Delta H_{\mathrm{tot}}}$

Both temperature and degree of cure fields within the sample thickness are considered uniform.

For the comparison purpose, heat flux density and temperature curves, obtained from PVT- $\alpha$ experiments done on vinylester resin in static pressure mode, are also plotted in Fig. 4a. A small difference in temperature profiles in the beginning can be observed, which is due to the different initial (room) temperatures, but once the heating started the temperature curves superimposed. It can also be noted that the both flux curves evolved in the same way, releasing the same amount of total heat of cure
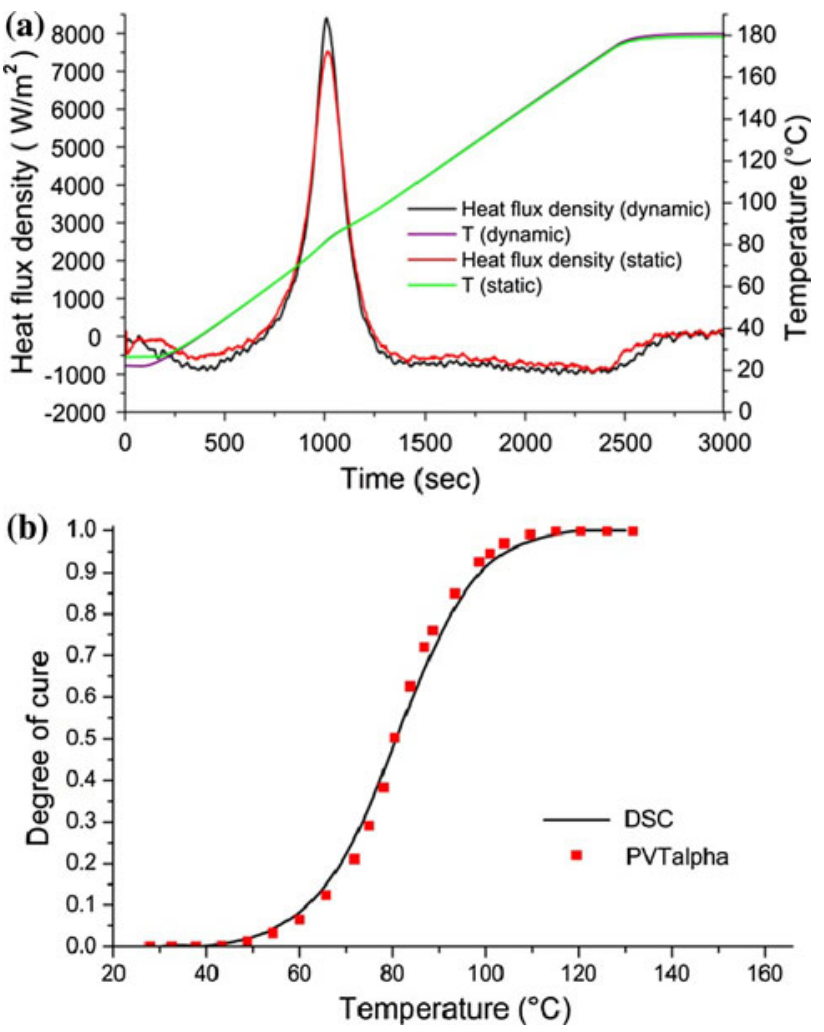

Fig. 4 a Heat flux density curves at static and dynamic pressures. b Comparison of degree of cure from DSC and PVT- $\alpha$

$325 \pm 4.2 \mathrm{~J} / \mathrm{g}$ (for three samples in each mode). Therefore, it can be concluded that quick pressure variations (as in our case) in a short time have no significant effect on the crosslinking kinetics, mould-sample thermal contact, and hence did not disturb the flux and temperature measurements.

Enthalpy of reaction and glass transition temperature of this resin were also determined using DSC (TA Q200 from TA Instruments ${ }^{\circledR}$ ) for comparison with the PVT- $\alpha$ measurements. The total heat of cure and glass transition temperature of fully cured resin were found equal to $324.9 \pm 3.6 \mathrm{~J} / \mathrm{g}$ and $118.9{ }^{\circ} \mathrm{C}$, respectively. Degree of cure found by integrating the heat flux density curve (by DSC) is also plotted in Fig. 4b. It can be noted that the results are in agreement with that found by PVT- $\alpha$ and demonstrated that PVT- $\alpha$ results are reliable.

Determination of thermal expansion and chemical shrinkage

Figure 5 shows the recorded thickness response (measurement of PVT- $\alpha$, which corresponds to the volume) of the resin sample versus time, when submitted to cyclic load during curing. Temperature is also plotted on the same figure. 




Fig. 5 Recorded thickness and temperature of sample (resin + silicon) versus time

Since resin was enclosed in a silicon capsule and placed in a steel mould, the first step was to remove the compression and possible thermal expansion of silicon, thermal expansion of steel mould, heat flux sensor and LVDT sensor from the experimental data.

For this purpose, an experiment was performed on a silicon disc under the experimental conditions similar to resin experiment. Thickness variation of silicon in the applied pressure cycle was subtracted from the recorded experimental data to get the thickness variation purely associated with the resin.

Minimum thickness points of this resin data are selected and plotted (named as lower curve) versus temperature in Fig. 6. The degree of cure calculated (Eq. 3) from heat flux density curve is also presented in the same graph. The same was done with maximum thickness points but not shown here to avoid repetition.

Thickness curve (lower) in Fig. 6 can be divided into three zones:

1. Neat resin zone (CD): when chemical reaction was not started and resin expands with temperature rise. Slope of thickness curve in this zone gives the volume coefficient of thermal expansion (CTE) of neat resin.

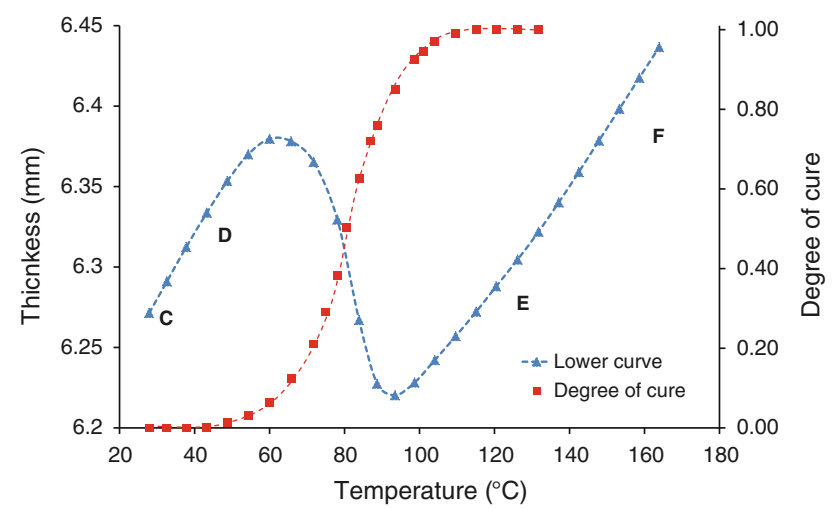

Fig. 6 Minimum thickness points (during load variation) versus temperature
2. Cross-linking zone (DE): in this zone chemical shrinkage appears with proceeding of chemical reaction in addition to thermal expansion, due to continuous rise of temperature.

3. Cured zone (EF): in this zone resin is fully cured but in the rubbery state due to $T>\mathrm{Tg}$. The slope of the thickness curve gives volume CTE of resin in the cured rubbery state.

In order to determine volume CTE in crosslinking zone (DE), a mixing law (4) was used

$\operatorname{CTE}(\alpha)=\operatorname{CTE}_{\text {uncured }}(1-\alpha)+\alpha \operatorname{CTE}_{\text {rubbery }}$

The upper curve corresponding to the maximum thickness points was treated in the same way and the calculated thermal coefficients of resin (for both curves) in cyclic pressure mode are presented in Table 1.

Once the coefficients of thermal expansion were determined, the next step was to calculate chemical shrinkage for both lower and upper curves. In the crosslinking zone, the volume chemical shrinkage $\left(d_{i} \operatorname{CS} \Delta \alpha\right)$ was obtained by subtracting thermal expansion from the experimental thickness $d(T, \alpha)$ as given in Eq. (5):

$d_{i} \operatorname{CS} \Delta \alpha=d(T, \alpha)-d_{i}(1+\operatorname{CTE}(\alpha) \Delta T)$

where $d_{i}$ is the initial thickness of the sample. CS is the volume coefficient of chemical shrinkage, which is defined as $\mathrm{CS}=\frac{\Delta d_{\text {shrinkage }}}{d_{i} \Delta \alpha}$. It has no unit.

Chemical shrinkage versus degree of cure for the lower curve is plotted in Fig. 7, which is found linear. This behaviour is in agreement with literature [6, 8, 39, 42]. Volume Coefficient of chemical shrinkage $\left(\mathrm{CS}_{1}\right)$ is equal to the slope of this plot and has the value of 0.068. Chemical shrinkage of upper curve was found in the same way giving the volume coefficient of chemical shrinkage $\mathrm{CS}_{2}$ equal to 0.07 .

Determination of bulk modulus

For the applied load, displacement of the thickness curve (Fig. 5) is higher in the beginning, as the resin was in the liquid state and was more compressible. With the proceeding of chemical reaction, the molecules got crosslinked, and magnitude of displacement started to change, which indicates the variation of compressibility. The objective here is 'to determine bulk modulus variation of the resin' from this data.

Table 1 Volume thermal coefficients of expansion of vinylester resin

\begin{tabular}{lll}
\hline Sample & $\mathrm{CTE}_{\text {liquid }}\left(K^{-1}\right)$ & $\mathrm{CTE}_{\text {rubbery }}\left(K^{-1}\right)$ \\
\hline Upper curve & $6.79 \times 10^{-4} \pm 1.5 \%$ & $6.10 \times 10^{-4} \pm 2.1 \%$ \\
Lower curve & $6.47 \times 10^{-4} \pm 2.8 \%$ & $5.58 \times 10^{-4} \pm 3.6 \%$ \\
\hline
\end{tabular}




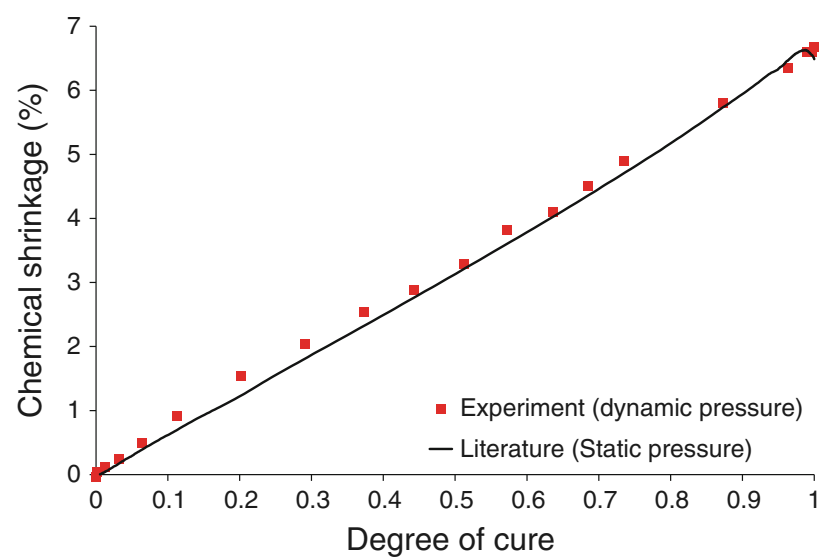

Fig. 7 Chemical shrinkage versus degree of cure, present experiment (for lower curve) and literature [42]

At first we will calculate bulk modulus for only one cycle. Figure 8 shows thickness variation versus temperature, for one pressure cycle while curing the sample. During the curing process, resin passed through a thermal expansion/contraction due to temperature variation, and the chemical shrinkage due to cross-linking of molecules in addition to its displacement due to applied load. Thus, the mechanical strain is coupled to thermal and chemical strains.

Consider $A\left(t_{1}, T_{1}, d_{1}, \alpha_{1}, P_{1}\right)$ and $B\left(t_{2}, T_{2}, d_{2}, \alpha_{2}, P_{2}\right)$ are the thickness peaks in this cycle. Here $t$ denotes the time instant, $T$ stands for temperature, $d$ is the thickness, $\alpha$ is degree of cure and $P$ is the pressure. The total displacement $\mathrm{AB}$ is equal to $\Delta d=d_{2}-d_{1}$. Similarly, $\Delta T=T_{2}-T_{1}$ and $\Delta \alpha=\alpha_{2}-\alpha_{1}$.

For the imposed pressure cycle, displacement $\mathrm{AB}$ was covered in $20 \mathrm{~s}$. Therefore, there was a temperature difference of $1.33{ }^{\circ} \mathrm{C}$ between $\mathrm{A}$ and $\mathrm{B}$ during the heating. If $A$ and B were in the curing zone, then as per Eq. (4) CTE might have changed with $\alpha$. Therefore, the value of CTE at the points $\mathrm{A}$ and $\mathrm{B}$ might not be the same. Since $A B$ is a small step (of order $10^{-5} \mathrm{~m}$ ), average of CTEs at the point $\mathrm{A}$ and $\mathrm{B}$ can be considered as the coefficient of thermal expansion at this step. Similarly, the average of the coefficients of chemical shrinkage can be taken as the value of $\mathrm{CS}$ at step $\mathrm{AB}$, i.e. $\mathrm{CS}_{\mathrm{AB}}=\frac{\mathrm{CS}_{1}+\mathrm{CS}_{2}}{2}$ and $\mathrm{CTE}_{\mathrm{AB}}=$ $\frac{\mathrm{CTE}_{1}+\mathrm{CTE}_{2}}{2}$

Here $\mathrm{CTE}_{1}$ and $\mathrm{CTE}_{2}$ are the thermal coefficients, and $\mathrm{CS}_{1}$ and $\mathrm{CS}_{2}$ are the chemical coefficients at point $\mathrm{A}$ and $\mathrm{B}$, respectively.

For any step $\mathrm{AB}$, total displacement $\Delta d$ can be written as sum of mechanical displacement $\left(\Delta d_{\text {mech }}\right)$, thermal expansion $\left(\Delta d_{\text {thermal }}\right)$ and chemical shrinkage $\left(\Delta d_{\text {shrinkage }}\right)$ :

$\Delta d(P, T, \alpha)=\Delta d_{\text {mech }}(P)+\Delta d_{\text {thermal }}(T, \alpha)-\Delta d_{\text {shrinkage }}(\alpha)$

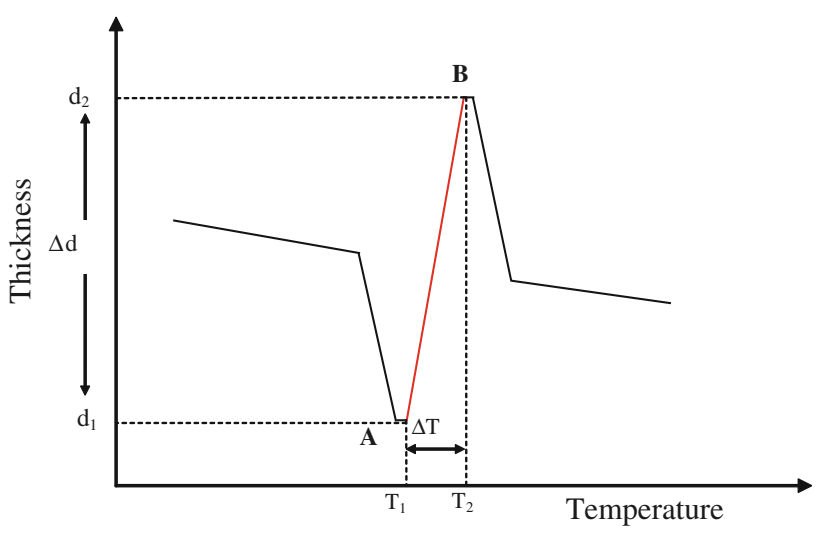

Fig. 8 Illustration of a cycle of thickness versus temperature during curing

with $\quad \Delta d_{\text {thermal }}(T, \quad \alpha)=d_{1} \cdot \mathrm{CTE}_{\mathrm{AB}} \quad(\alpha) . \Delta T$; $\Delta d_{\text {shrinkage }}=d_{1} \cdot \mathrm{CS}_{\mathrm{AB}} \cdot \Delta \alpha$.

Knowing the coefficients of thermal expansion and chemical shrinkage, Eq. (6) was solved for each cycle to calculate $\Delta d_{\text {mech }}$.

Compressive stresses $\sigma_{1}$ and $\sigma_{2}$ at points $\mathrm{A}$ and $\mathrm{B}$ of a given step $\mathrm{AB}$, respectively, were calculated taking ratios of compressive loads to the surface areas of resin disc at these points. By knowing the values of compressive stresses and displacement $\Delta \mathrm{d}_{\text {mech }}$, the bulk modulus at the step $\mathrm{AB}$ was found using Eq. (7).

$K_{\mathrm{AB}}=\frac{\left[\sigma_{1}-\sigma_{2}\right]}{\left[\Delta d_{\mathrm{mech}} / d_{1}\right]}$

\section{Evolution of bulk modulus during curing}

Using (7), bulk modulus of the vinylester resin was calculated for all the load cycles, which is plotted versus sample surface temperature in Fig. 9a. Degree of cure, calculated from heat flux density curve, is also plotted on the same graph. The results were found reproducible. It was noted that bulk modulus started to increase from $55{ }^{\circ} \mathrm{C}$, which corresponds to the gel point $(\alpha=0.08)$ of the vinylester resin [43]. This behaviour continues until the temperature reaches $115-118{ }^{\circ} \mathrm{C}$ (fully cured state as $\alpha=1$ ), where the resin acquires maximum bulk modulus value $(2.72-\mathrm{GPa})$.

On further increasing the temperature, the resin was converted to a rubbery solid. This change of state resulted in the fall of bulk modulus, which seems normal. The decrease in bulk modulus on heating above $\mathrm{Tg}$ is found quasi-linear.

In general, evolution of mechanical properties during curing is presented versus degree of cure. Therefore, it was interesting for us to plot the bulk modulus versus degree of cure. This degree of cure was calculated from experimental heat flux density measured by heat flux sensors. 

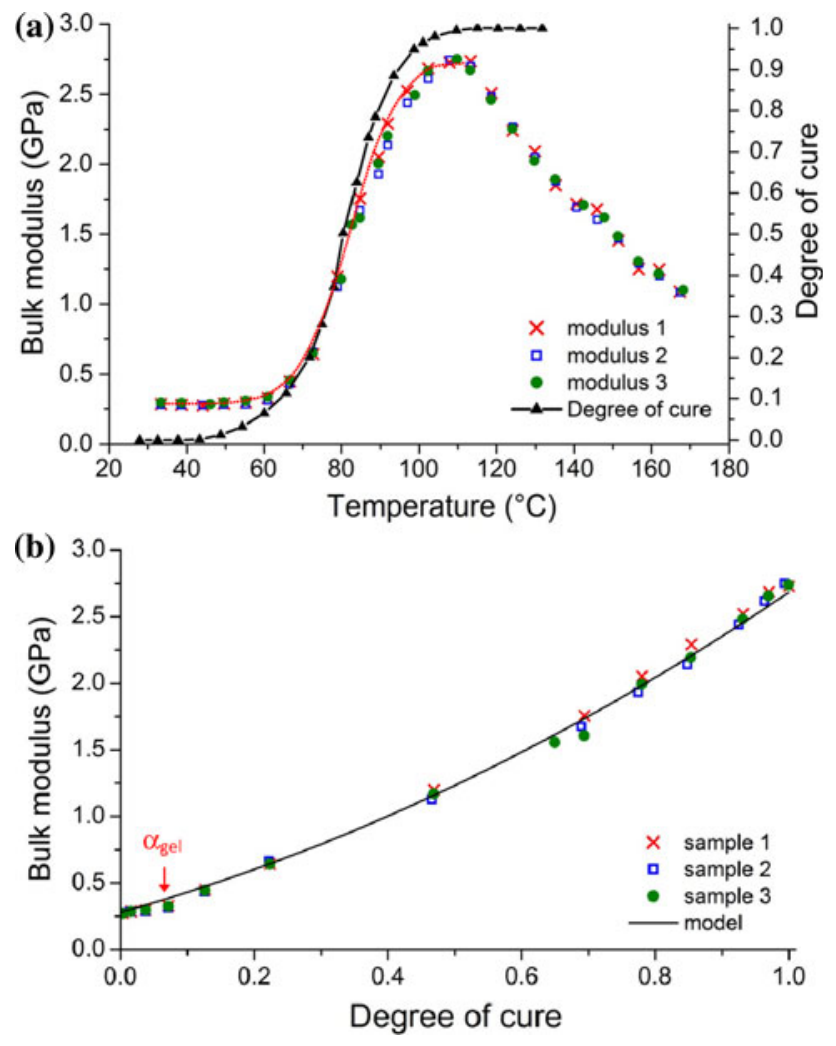

Fig. 9 a Evolution of bulk modulus and degree of cure versus temperature. $\mathbf{b}$ Evolution of bulk modulus versus reaction conversion degree

Figure $9 \mathrm{~b}$ shows the bulk modulus of vinylester resin versus degree of cure. It can be noted that bulk modulus remained constant until $\alpha_{\text {gel }}$, however from this point a significant increase can be observed with the increase in degree of cure. Moreover, the evolution of bulk modulus with respect to degree of cure is nonlinear.

Keeping in view the experimental results, an empirical expression is proposed here to model the evolution of bulk modulus as a function of the degree of cure. If $K_{1}$ is the bulk modulus of the liquid uncured resin and $K_{2}$ is of solid cured resin, then $K$ at any point during the curing can be found by:

$K(\alpha)=K_{1}+\left[\alpha^{2}+\frac{\alpha K_{2}}{2}\right]$

Using (8), evolution of $K$ as function of $\alpha$ is calculated and is presented (model curve) in Fig. 9b, which shows that the model is able to predict accurately the evolution of the bulk modulus.

\section{Calculation of tensile modulus evolution}

The evolution of tensile modulus of resin or composite is very important to model the residual stresses and shape evolution of a composite part while curing. Knowing the evolution of bulk modulus, evolution of tensile modulus can be found easily by the classical equation of mechanics (9).

$$
K=\frac{E}{3(1-2 v)}
$$

where $v$ is the Poisson's ratio and E denotes the Young's modulus. Evolution behaviour of Young's modulus during curing can be modelled by Eq. (9).

$E(\alpha)=E_{1}+3 \alpha^{2}(1-2 v)+\frac{\alpha E_{2}}{2}$,

where $E_{1}$ is the tensile modulus of neat resin and $E_{2}$ is the tensile modulus of fully cured resin. There will be an evolution of Poisson's ratio for the resin and composite. An additional experimental technique, e.g. extensometer gauges, is needed to measure Poisson's ratio and hence to calculate Young's modulus using Eq. 10.

\section{Determination of thermal conductivity}

For determination of thermal conductivity, guarded hot plate technique [37] was used to measure the thermal conductivity $(\lambda)$ of cured resin between 25 and $75^{\circ} \mathrm{C}$. A transient technique based on an optimization approach, was also applied to determine the thermal conductivity of resin in both raw and cured resin states [38]. A thermocouple was inserted in the centre of the silicon capsule (Fig. 10a) cavity before sealing it. The resin was injected in capsule using syringes and vacuum assistance. This capsule was then placed in PVT- $\alpha$ mould for the curing. Thermocouple at the centre of the sample disc $(6 \mathrm{~mm})$ provided the temperature measurement done at the centre of the sample. Surface temperatures determined from heat flux sensors were used as boundary conditions. Identification of thermal conductivity was done by minimizing a least square criterion using the conjugate gradient algorithm. The gradient of the criterion was determined by solving a set of adjoint equations [44]. The results are presented in Fig. 10b. Thermal conductivity versus temperature results were fitted using linear regressions (11)(13). It can be noticed that thermal conductivity of neat resin increased with temperature until $70{ }^{\circ} \mathrm{C}$, but after that it became constant. For cured resin, thermal conductivity increased with temperature until $\mathrm{Tg}$ but after that a fall in conductivity was observed with the temperature rise. Moreover, the results of hot guarded plate are in agreement with the results of this method.

$\lambda=0.165\left(\mathrm{Wm}^{-1} \mathrm{~K}^{-1}\right)\left(\right.$ neat resin, $\left.20^{\circ} \mathrm{C}<T<70^{\circ} \mathrm{C}\right)$

$$
\lambda=1.41 \times 10^{-4} T+0.187\left(\mathrm{Wm}^{-1} \mathrm{~K}^{-1}\right)
$$

$$
\text { (cured resin, with } T \text { in }{ }^{\circ} \mathrm{C}, T<T g \text { ) }
$$




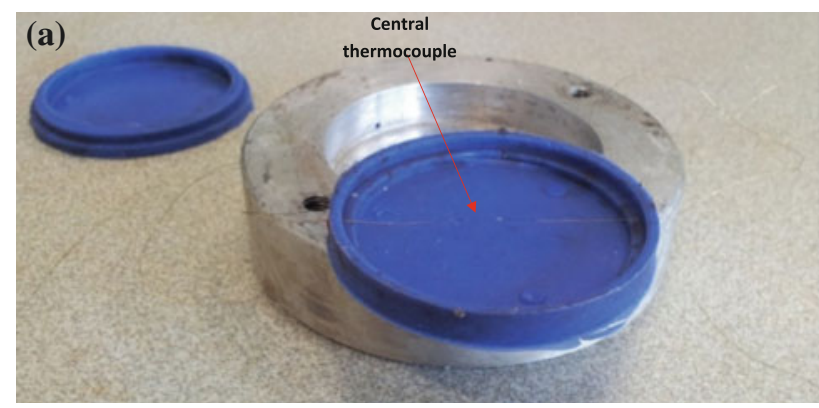

(b)

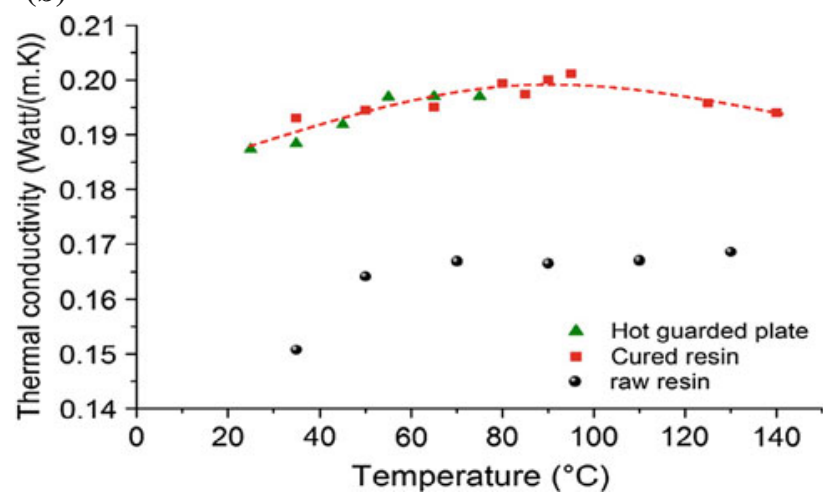

Fig. 10 a Thermocouple inserted in the centre of capsule before sealing and resin infusion. b Thermal conductivity versus temperature for both techniques

$$
\begin{aligned}
\lambda= & -1.63 \times 10^{-4} T+0.216\left(\mathrm{Wm}^{-1} \mathrm{~K}^{-1}\right) \\
& \left(\text { cured resin, with } T \text { in }{ }^{\circ} \mathrm{C}, T>T g\right) .
\end{aligned}
$$

\section{Conclusion}

In the present study, PVT- $\alpha$ mould, which is a multifunctional polymer/composite testing device, was adapted and used for the first time in the dynamic pressure mode to identify experimentally, the evolution of bulk modulus of resin during the cure. Chemical shrinkage and degree of cure were determined from the same experiment and were found in agreement with literature results. Thermal conductivity was also determined using the same device.

Bulk modulus started to develop from $\alpha_{\text {gel }}$, and then increased with the increment in degree of cure. The resin gained a maximum value of $2.72 \mathrm{GPa}$ in the fully cured state. This modulus dropped on the temperatures higher than $\mathrm{Tg}$, which is normal as the resin was converted to the rubbery state. A mathematical model, for evolution of bulk modulus depending on degree of cure, was proposed, which successfully fitted the experimental data. Evolution of Young's modulus of resin and composites can be calculated from the values of bulk modulus by the proposed model. However, to calculate the Young's modulus, additional information on the evolution of Poisson's ratio will also be required, which can be found using the experimental techniques, like strain gauges, etc.

Thermal conductivity of neat and fully cured resin was found dependent on temperature and its physical state. For fully cured resin, analysis was done in both glassy and rubbery state. It was found that the thermal conductivity increases with the temperature rise until the glass transition temperature $(\mathrm{Tg})$ but at the temperatures higher than the $\mathrm{Tg}$, it decreases with the increase in temperature. The obtained results were validated with conventional hot guarded plate method results.

\section{References}

1. Wisnom MR, Gigliotti M, Ersoy N, Campbell M, Potter KD (2006) Compos A Appl Sci Manuf 37(4):522-529

2. Nawab Y, Jacquemin F, Casari P, Boyard N, Sobotka V (2012) J Compos Mater. doi:10.1177/0021998312440130

3. Genidy MS, Madhukar MS, Russell JD (1999) J Reinf Plast Compos 18(14):1304-1321. doi:10.1177/073168449901801403

4. Motahhari S, Cameron J (1999) J Reinf Plast Compos 18(11):1011-1020. doi:10.1177/073168449901801104

5. Schick C (2009) Anal Bioanal Chem 395(6):1589-1611. doi:10.1007/s00216-009-3169-y

6. Nawab Y, Tardif X, Boyard N, Sobotka V, Casari P, Jacquemin F (2012) Compos Sci Technol 73:81-87. doi:10.1016/j.compscitech. 2012.09.018

7. Boyard N, Vayer M, Sinturel C, Erre R, Delaunay D (2003) J Appl Polym Sci 88(5):1258-1267

8. Hoa SV, Ouellette P, Ngo TD (2009) J Compos Mater 43(7):783-803. doi:10.1177/0021998308102035

9. Li C, Potter K, Wisnom MR, Stringer G (2004) Compos Sci Technol 64(1):55-64

10. Snow AW, Armistead JP (1994) J Appl Polym Sci 52(3):401-411

11. Yan-Jyi H, Chiou-Ming L (1996) Polymer 37:401-412

12. Mark K, Lee LJ (1992) J Appl Polym Sci 45(1):37-50

13. Mark K, Shailesh M, Lee LJ (1995) Polym Eng Sci 35(10): 823-836

14. Madhukar MS, Genidy MS, Russell JD (2000) J Compos Mater 34(22):1882-1904. doi:10.1106/hucy-dy2b-2n42-ujbx

15. Parlevliet PP, Bersee HEN, Beukers A (2010) Polym Testing 29(4):433-439

16. Shah DU, Schubel PJ (2012) Polym Test 29(6):629-639

17. Schoch KF, Panackal PA, Frank PP (2004) Thermochim Acta 417(1):115-118

18. Parlevliet PP, Bersee HEN, Beukers A (2010) Polym Testing 29(3):291-301

19. Antonucci V, Giordano M, Cusano A, Nasser J, Nicolais L (2006) Compos Sci Technol 66(16):3273-3280. doi:10.1016/j.compscitech. 2005.07.009

20. Karalekas D, Cugnoni J, Botsis J (2008) Compos A Appl Sci Manuf 39(7):1118-1127. doi:10.1016/j.compositesa.2008.04.010

21. Giordano M, Laudati A, Nasser J, Nicolais L, Cusano A, Cutolo A (2004) Sens Actuators A 113(2):166-173. doi:10.1016/ j.sna.2004.02.033

22. Vacher S, Molimard J, Gagnaire H, Vautrin A (2003) Polym Polym Compos 12(4):269-276

23. Tai HJ, Chou HL (2000) Eur Polymer J 36:2213-2219

24. Lange J, Toll S, Månson J-AE, Hult A (1995) Polymer 36(16): 3135-3141 
25. Yang DG, Jansen KMB, Ernst LJ, Zhang GQ, Bressers HJL, Janssen JHJ (2007) Microelectron Reliab 47(2-3):233-239. doi:10.1016/j.microrel.2006.09.031

26. Boyard N, Vayer M, Sinturel C, Erre R, Delaunay D (2004) J Appl Polym Sci 92(5):2976-2988. doi:10.1002/app.20312

27. Abou Msallem Y, Jacquemin F, Boyard N, Poitou A, Delaunay D, Chatel S (2010) Compos A Appl Sci Manuf 41(1):108-115. doi:10.1016/j.compositesa.2009.09.025

28. Holst M, Schänzlin K, Wenzel M, Xu J, Lellinger D, Alig I (2005) J Polym Sci Part B Polym Phys 43(17):2314-2325. doi:10.1002/polb.20519

29. Hearn EJ (1997) Mechanics of materials 1, 3rd edn. Butterworth Heinemann, Oxford, UK

30. Yang BJ, Kim BR, Lee HK (2012) Acta Mech 223(6): 1307-1321. doi:10.1007/s00707-012-0651-y

31. Gigliottia M, Molimard J, Jacquemin F, Vautrin A (2006) Compos A Appl Sci Manuf 37(4):624-629

32. Nawab Y, Jacquemin F, Casari P, Boyard N, Sobotka V (2012) Key Eng Mater 504:1145-1150

33. Mott PH, Dorgan JR, Roland CM (2008) J Sound Vib 312(4-5):572-575. doi:10.1016/j.jsv.2008.01.026

34. Dixon S, Jaques D, Edwards C, Palmer SB (2003) AIP Conf Proc 657(1):1049-1055. doi:10.1063/1.1570249
35. Plepys AR, Farris RJ (1990) Polymer 31(10):1932-1936. doi:10.1016/0032-3861(90)90019-u

36. Lindrose A (1978) Exp Mech 18(6):227-232. doi:10.1007/ bf02328418

37. David S (2001) Meas Sci Technol 12(12):R89

38. Bailleul JL, Delaunay D, Jarny Y (1996) J Reinf Plast Compos 15(5):479-496. doi:10.1177/073168449601500503

39. Nawab Y, Boyard N, Sobotka V, Casari P, Jacquemin F (2012) Key Eng Mater 504:1129-1134

40. Boyard N, Millischer A, Sobotka V, Bailleul JL, Delaunay D (2007) Compos Sci Technol 67(6):943-954

41. Beck JV, Blackwell B, Clair CS (1985) Inverse heat conduction. Wiley, New York

42. Nawab Y, Boyard N, Sobotka V, Casari P, Jacquemin F (2011) Adv Mater Res 326:19-28

43. Lee JH, Lee JW (1994) Polym Eng Sci 34(9):742-749. doi:10.1002/pen.760340907

44. Tardif X, Agazzi A, Sobotka V, Boyard N, Jarny Y, Delaunay D (2012) Polym Testing 31(6):819-827. doi:10.1016/ j.polymertesting.2012.05.008 